\title{
Federico García Lorca y la música
}

\author{
Federico García Lorca and music
}

\author{
Marco Antonio de la Ossa Martínez \\ Universidad de Castilla-La Mancha \\ marco.ossa@uclm.es \\ ORCID iD: https://orcid.org/0000-0002-9707-879X
}

\section{RESUMEN}

Federico García Lorca (1898-1936) es, sin duda, una de las grandes figuras más destacadas en la historia del arte del siglo XX. Es bien conocida, subrayada, representada y ha sido ampliamente estudiada su faceta de poeta, dramaturgo y ensayista. Pero, quizá, su enorme vinculación con la música y el gran espacio que brindó a este arte siga siendo uno de los perfiles más desconocidos en una personalidad que podemos definir como poliédrica.

En este artículo nos acercaremos brevemente a su formación musical, ya que la música fue la primera vocación de Federico. También nos aproximaremos a la biblioteca musical que poseyó, muy interesante en muchos sentidos, y a las múltiples referencias musicales que plasmó en sus poemas, dramas y escritos. En definitiva, trataremos de conocer al Federico pianista, compositor, investigador y conferenciante, ya que dictó numerosas ponencias con la música como protagonista. Por último, también subrayaremos la amistad que le unió con grandes personalidades de la música de su momento, entre los que destacó Manuel de Falla.

Palabras clave: Federico García Lorca, investigación musical, Manuel de Falla, flamenco, música tradicional.

\section{Abstract}

Federico García Lorca (1898-1936) is undoubtedly one of the great international figures of twentieth century art. She is well known, underlined, represented and her facet of poet, playwright and essayist has been widely studied. But, perhaps, its enormous connection with music and the great space it offered to this art remains one of the most unknown profiles in a personality that we can define as polyhedral. 


\section{MARCO ANTONIO DE LA OSSA MARTÍNEZ}

In this paper we will approach his musical training, since music was the first vocation of Federico. We will also approach the musical library that he owned, very interesting in many ways, and the multiple musical references that he expressed in his poems, dramas and writings. In short, we will try to approach the Federico pianist, composer, researcher and lecturer, since he dictated numerous presentations with music as the protagonist. Finally, we will not forget to underline the friendship that united him with great personalities of the music of his time, among which Manuel de Falla stands out.

Key words: Federico García Lorca, poetry and music, folk music, Manuel de Falla, flamenco, musicology.

Ossa Martínez, M. A. de la (2018). Federico García Lorca y la música. Cuadernos de Investigación Musical, 2018, 6 (extraordinario), 334-350.

doi: 10.18239/invesmusic.v0i0.1950

\section{ACERCAMIENTO A LA FIGURA DE LORCA: EDUCACIÓN Y FORMACIÓN MUSICAL}

Sin duda alguna, se han escrito infinidad de libros, textos y monografías sobre Federico García Lorca, su vida y trayectoria profesional. En una gran cantidad de ellos, además, se ha abordado con profundidad y criterio sus treinta y ocho años de recorrido personal, el corpus literario que legó, su personalidad y el trágico asesinato que puso fin a su existencia. Pero la gran vinculación que tuvo Federico con la música y el reflejo que ésta tuvo en su vida y obra es una vertiente del artista a destacar, mencionar y celebrar.

Tal es así que, durante su adolescencia y en la primera etapa de su juventud, Federico era considerado como músico en su ambiente cercano. En esos instantes, estudiaba piano y solía tocar diferentes obras en público con gran frecuencia. Es más: según Jorge de Persia, "su personalidad se perfilaba como la de un músico en potencia" (1999: 67-68), tal y como se puede entrever tras analizar diferentes textos y biografías dedicados al granadino. Después, cuando la literatura tomó mayor espacio en su producción, la cercanía entre poesía, teatro y música, de la misma manera que ocurriría en diferentes autores dentro de la generación en la que se inscribió, la del 27, fue muy profunda.

Como es bien conocido, el artista fue asesinado poco después del comienzo de la contienda por el bando sublevado en las inmediaciones de Víznar, en la provincia de Granada. Su cuerpo fue enterrado en una fosa común, por lo que, hoy en día, todavía no se conoce su paradero. Los motivos de su muerte han sido comentados en multitud de ocasiones: su homosexualidad, el conocido apoyo que brindó a la Segunda República (1931-1936), varias y variadas enemistades y envidias que surgieron en su ciudad y, en otros puntos debido a su éxito y personalidad, el hecho de que su cuñado fuera alcalde socialista de Granada en el momento de la sublevación o el reflejo de personajes reales y contemporáneos suyos en uno de sus últimos dramas, La casa de Bernarda Alba, son solo algunos de los condicionantes que se han ido esgrimiendo con el paso de los años en el 


\section{FEDERICO GARCÍA LORCA Y LA MÚSICA}

imposible intento de explicar los porqués de un acto horrendo que, como en el triste y trágico caso de otros miles de españoles, jamás debiera haber tenido lugar.

Como mencionamos, todavía queda un notable trabajo que llevar a cabo para remarcar y situar en el lugar que merece la vinculación de Lorca con la música. En este sentido y en primer lugar, debemos atender al ambiente familiar en el que se crió, ya que el arte de Orfeo tenía una presencia bastante notoria, tal y como describió Tinell (1993):

Su tío Luis García Rodríguez toca el piano y canta; su tía Isabel García Rodríguez le empieza a enseñar a tocar la guitarra siendo él aún muy joven. Con su prima hermana, Clotilde García Picossi, Federico aparece por primera vez sobre las tablas haciendo de meritorio con tres o cuatro años en la zarzuela "La alegría de la huerta" que se representó en Fuente Vaqueros. De las criadas aprende nanas y otras canciones populares de Andalucía. Muy pronto muestra la gran facilidad que tiene para la música. La madre de Federico, doña Vicente Lorca Romero, maestra de escuela antes de su matrimonio, tiene un interés especial por la música y hace todo lo posible para dotar a sus hijos de una enseñanza musical y para que aprendan a tocar el piano (1993: 9).

La música en su casa era una constante, por lo que desde muy temprana edad estuvo en contacto directo con ella en múltiples formas. Su madre, Vicenta Lorca, casada con Federico García Rodríguez en segundas nupcias y maestra de escuela de profesión (dejó de trabajar tras el matrimonio), tuvo como premisa que sus hijos se formaran musicalmente. Afirmó en numerosas ocasiones que Federico mostró desde muy pequeño mucho interés por la música, sobre todo por las canciones tradicionales y por la guitarra, instrumento que le encantaba. Como el propio Lorca comentó, "mi infancia es aprender letras y música con mi madre" (Martín, 2010: 63).

Comenzó su formación musical reglada durante su estancia en Almería en un colegio de los padres escolapios en el que fue matriculado cuando contaba con siete años. A su regreso a Granada, en 1909, continuó sus estudios musicales formándose en piano y armonía. Incluso, hasta que alcanzó los dieciocho años de edad la música fue el camino elegido por Federico para desarrollarse principalmente en la vida. Según diferentes opiniones, entre las que destacamos la de Ian Gibson, alcanzó un muy buen nivel y no fue difícil verle protagonizar recitales:

Lorca se convierte en tan excelente pianista que se le augura una distinguida carrera musical. Todavía no ha surgido la vocación literaria, y en los viajes de estudios de 1917 y 1917 por Andalucía, Castilla, Galicia y León, con el catedrático de Arte Martín Domínguez Berruela, Federico es "el músico" del grupo de alumnos [...] que deleita al público tocando a clásicos y modernos e interpretando, de vez en cuando, sus propias composiciones (1987: 81). 


\section{MARCO ANTONIO DE LA OSSA MARTÍNEZ}

La intensidad de esta vocación musical fue señalada en numerosas ocasiones por los propios familiares de Federico. Por ejemplo, Francisco García Lorca, su hermano, remarcó la presencia de la música en su vida. Incluso, sus compañeros de la facultad de Granada le consideraban el músico del grupo, y algunas de las piezas que compuso, de carácter breve, consiguieron cierta aceptación:

Quizá la música fue la primera tendencia artística que empezó a cuajar en el alma de mi hermano. Sus primeras páginas publicadas revelan este arrastre musical. Se ve en ellas también cómo una visión plástica, casi pictórica, del mundo viene dominada por unas ideas de armonía, que tienden a una primera ordenación de su mundo adolescente. Supone éste unas fuerzas ciegas, enfrentadas por una sumisión misteriosa a leyes de armónica correspondencia, que elevan hasta lo negativo y lo terrible la tentación de la carne y la furia de la naturaleza, hacia un acorde último que une los vacíos estelares al élitro del diminuto insecto. Todo este sistema de "correspondencia" encuentra su cauce primero en la música, y sus primeras páginas son una proyección, no exenta de angustia, de esta armonía apasionada (1999: 158).

Dos situaciones frenaron este impulso vital y profesional: la primera de ellas fue la muerte de su admirado profesor de piano Antonio Segura en octubre de 1916. El poeta, además de un gran apoyo, perdía su principal valedor ante sus padres, ya que pensaba marchar a París a continuar sus estudios musicales. Pero no contó con la aprobación de su familia, ya que, según narra Gibson su padre "no estaba convencido de que Federico tuviera auténtica vocación musical y, en cualquier caso, creía que su hijo mayor debía contar por lo menos con un título académico antes de lanzarse a cualquier aventura" (2003: 72).

Esta pérdida, junto a la negativa final de sus padres a que marchara a Francia para proseguir su formación, terminó por distanciarle de su deseo de continuar sus estudios en la capital gala y apartó progresivamente de su mente la idea de dedicarse profesionalmente a la música. Pese a la capacidad para la improvisación que poseía, también pudo apreciar algunas limitaciones compositivas propias. Para Gibson, tal vez no encontró la inspiración para componer que hubiera deseado:

Federico acabaría venerando a su viejo maestro que, al tiempo que estimulaba su talento musical innato y le ayudaba a adquirir una excelente técnica pianística y unos conocimientos sólidos de la armonía, le iba cogiendo mucha confianza. Incluso le solía hablar con resignación de los altibajos de su vida de compositor fracasado. "Que yo no haya alcanzado las nubes no quiere decir que las nubes no existan", insistía. Lorca no se cansaba nunca de repetir aquella frase "con emoción religiosa" a sus amigos (2003: 66-67). 


\section{FEDERICO GARCÍA LORCA Y LA MÚSICA}

Pero tras la muerte de Segura no terminaron los estudios de piano, sino que Juan Benítez, organista de la catedral de Granada, se convirtió en su tercer profesor. También causó una honda huella en su alumno, sobre todo en los años de universidad. Según contaron algunos amigos, Lorca siguió mostrando mucha vehemencia en el estudio e interpretación de algunas piezas que le agradaban por distintos motivos.

En múltiples cartas, encontramos testimonios en los que el propio Federico subrayó de primera mano la dedicación que brindó a la música en general y al piano en particular. Así lo apunta él mismo en una misiva dirigida a su madre fechada en 1910: "querida mamá y tita: tengo mucha gana de verte. Yo estoy estudiando mucho y las lecciones de piano he dado 7 ejercicios y me han puesto la 4 [sic] melodía. Recibe un cariñoso beso de tu hijo que te quiere mucho" (García Lorca, 2005: 10).

En este sentido, sobresale el texto que dedicó a su piano, el instrumento que los Lorca tenían en su casa de Granada. Queda en evidencia el disfrute y tiempo dedicado por el poeta a este teclado:

En un rincón oscuro está mi piano durmiéndose. Un gran manto rojo lo cubre... Muchas veces con el silencio sus cuerdas viejas vibran suaves y se mueve todo él muy lánguidamente... Huele a viejo y sus teclas son de amarillo por el tiempo. ¿Qué tienes, mi adorado piano, en que tocó la abuela? ¿Por qué vibras en la noche sin que te hable nadie? ¿Acaso tienes un alma en pena escondida en tus secretos...? Viejo piano mío, jtú eres mi amigo y mi expresión! Cuando pulso tus teclas sueño y soy feliz. ¿Quién te arrancara tu supremo acorde! Si tú me pudieras abrazar, yo olvidaría lo que sabes. Yo te amo sobre todas las cosas. Déjame que te bese y que te haga cantar... (2007: 140-141).

Además, numerosos amigos remarcaron en diferentes escritos la aptitud y actitud de Lorca hacia la música. Cabe citar lo señalado por Jorge Guillén:

Más influyente que la pintura fue la música. Todos sabemos que en Federico resaltaba un gran temperamento de músico, acrecentado por la vigilia estudiosa. Habría podido ser compositor si se lo hubiese propuesto. Se contentó con ser de verdad un aficionado muy competente. En música fue tal vez donde el gusto de Federico se refinó con más pureza (García Lorca, 1977: 36).

Incluso, en una entrevista que concedió a Pablo Suero el 14 de octubre de 1933, el propio Lorca declaró con seriedad: "yo ante todo soy músico" (2006: 416). En el momento de pronunciar estas palabras, la conversación se centraba en una conferencia que el granadino iba a dictar en la capital argentina, Cómo canta una ciudad de noviembre a noviembre. Al parecer, también causaron un gran revuelo las palabras del compositor Ernesto Halffter, quien apuntó: "en mi país hay tres grandes músicos: Falla, mi maestro; yo, que soy su discípulo, y Federico García Lorca" (García Lorca, 2006: 416). Como vemos y por lo tanto, 


\section{MARCo ANTONIO DE LA OSSA MARTÍNEZ}

otros músicos de renombre y prestigio también señalaron la aptitud y actitud del poeta hacia la música.

Retornando a su etapa de juventud, pronto se convirtió en un buen intérprete, tal vez no virtuoso pero sí dotado de musicalidad y duende, un término que defendió en numerosas ocasiones. Conocía, disfrutaba e interpretaba al piano los repertorios de los principales compositores de música culta. También compuso algunas obras, como podemos entender al leer una tarjeta postal que envió desde Ávila en octubre de 1916. En ella, indica que interpretó composiciones suyas, aunque desconocemos sus nombres: "por la noche, estupenda velada en el Instituto. [Luis] Mariscal me presentó y toqué al piano cosas mías que me aplaudieron y felicitaron muchísimo" (García Lorca, 2005: 14). En este sentido, también se han conservado algunas partituras escritas por el granadino, eso sí, muchas de ellas incompletas.

Como podemos apreciar, en las múltiples cartas que envió a algunos de sus familiares y amigos, Lorca hizo referencia a algunas de las muchas ocasiones en que se sentó al piano delante del público. En una misiva de julio de 1929 que envió desde Nueva York podemos hallar otro ejemplo. Él mismo remarcó una palabra para destacar las múltiples peticiones e interés que despertaron en su estancia en la ciudad estadounidense sus estudios e interpretaciones de la música tradicional andaluza y española. También subrayó su amplio conocimiento sobre el ámbito de la canción: "y allí hubo una pequeña fiesta, en la cual 'inevitablemente' tuve que tocar y cantar al piano. No tenéis idea lo que se emocionan estos americanos con las canciones de España. Yo tengo lo que se llama un lleno" (García Lorca, 2005: 483-484).

En el mismo sentido, en otra de las comunicaciones que llevó a cabo por carta con su familia desde los Estados Unidos en 1929 destacó la gran acogida de algunas de sus canciones por parte de la variada audiencia que se daba cita en estas reuniones:

Había un muchachillo que cantó cantos religiosos. Yo me senté en el piano y también canté. Y no quiero deciros lo que les gustaron mis canciones. Las "moricas de Jaén", el no salgas, paloma, al campo", y "el burro" me las hicieron repetir cuatro o cinco veces" (García Lorca, 2005: 479-480).

Continuando esta línea, su estancia en la Residencia de Estudiantes de Madrid, de la que marchó en 1928, fue muy productiva, ya que en ella tomó contacto con personalidades muy diversas del mundo del arte, como Salvador Dalí, el cine (Luis Buñuel), la música, la literatura... A través de las múltiples conferencias que se dedicaron a la música tradicional, también entró en contacto con un buen número de cancioneros. Entre ellos, destaca el editado por Eduardo Martínez Torner sobre música asturiana y otros anteriores, como los de Pedrell o Barbieri.

Además, son numerosas las referencias a un Lorca que solía tocar el Bechstein y el Pleyel con los que contaba la residencia. Así, Jorge Guillén recuerda a Alberti haciendo referencia a estas veladas en las que interpretaba canciones tradicionales: 


\section{FEDERICO GARCÍA LORCA Y LA MÚSICA}

Rafael Alberti, evocando el Pleyel de la Residencia de Estudiantes, resucita aquellas "tardes y noches de primavera o comienzos de estío pasados alrededor de un teclado, oyéndole subir de su río profundo toda la millonaria riqueza oculta, toda la voz diversa, honda, triste, ágil y alegre de España" (1977: 48).

\section{LORCA, LA GENERACIÓN DEL 27 Y MANUEL DE FALLA}

Como hemos visto, podemos afirmar que, en su primera etapa, Federico se centró en mayor medida en la música culta. Pero, paulatinamente, también mostró un gran interés por la música tradicional, y llevó a cabo numerosas investigaciones, algunas de ellas junto al filólogo, historiador y musicólogo Ramón Menéndez Pidal. En ellas, trató de recuperar y recopilar canciones y romances en los pueblos. Por tanto, todo este acervo popular inspiró y estuvo presente de forma clara en su obra literaria, como mencionó Vals Gorina:

De este organismo -el pueblo- que en España ha mantenido incontaminados e intactos sus principios culturales, se nutre gran parte de la obra de Federico García Lorca, tanto en su esfera poética ("Romancero gitano", "Poema del cante jondo", etc.) como en su ámbito escénico en el que, sus personajes, o son gente del pueblo ("Yerma", "Bodas de sangre") o es de raíz popular su intención y montaje técnico ("El Retablo de Don Perlimplin") o tiene a la mentalidad de todo un pueblo como protagonista ("La casa de Bernarda Alba") (1962: 96).

Como consecuencia directa, García-Posadas ha señalado que el amplio conocimiento que tuvo sobre las formas y géneros musicales también tuvo un amplio espacio en su corpus literario:

Su obra, que revela un sentido musical de primera mano, un sorprendente trasvase a la literatura de estructuras y módulos musicales, la apropiación de un puñado de intuiciones hondas de la canción popular, incluido el cante flamenco, la sedimentación en su escritura de elementos y motivos germinados de la memoria colectiva (2005: 16).

No podemos olvidar la enorme relación entre literatura y música en la Generación del 27. Así, numerosos miembros de este grupo a las composiciones de sus contemporáneos con gran interés, un hecho que no había acontecido en momentos anteriores en España. Una gran cantidad de ellos, incluso, apoyaron abiertamente con su presencia y sus escritos estrenos de obras de coetáneos españoles y extranjeros en nuestro país. Además, algunos de ellos destacaron por su vertiente musical y las colaboraciones con músicos que llevaron a cabo: Jorge Guillén, Rafael Alberti, Gerardo Diego, Luis Cernuda, José Bergamín, Fernando Vela... 


\section{MARCo ANTONIO DE LA OSSA MARTÍNEZ}

Como comentamos, la presencia de la música en la vida de Lorca fue más que notable. Por ello, marcó numerosísimas referencias musicales en sus obras literarias. Su profunda amistad con Manuel de Falla, ya mencionada anteriormente, fue muy relevante en este sentido. El poeta mostró un enorme aprecio y valoración por el compositor en muchos escritos, sentimientos completamente correspondidos. Uno de ellos es esta pequeña reseña publicada en una revista en la que señala su alegría por el triunfo del gaditano en un estreno celebrado en París:

...necesita expresar el inmenso júbilo que le ha producido el éxito clamoroso alcanzado en París por el maestro. Claro que Falla tiene, no sólo en París, sino que el mundo civilizado, un éxito continuo que se afirma y crece de una manera constante, como un gran río que no puede ya marchar sin que su caudal sea cada vez más rico (García Lorca, 2006: 310).

El 15 de octubre de 1933 también habló del autor del Concierto para clave y orquesta. En una entrevista firmada por Pablo Suero, señaló su carácter bondadoso, generoso y trabajador:

Un día recibió diez mil pesetas. A mí y a otros amigos nos pidió que averiguáramos de gente que necesitase un ayuda de dos o tres mil pesetas. "Busquen ustedes -nos dijo- esa gente que vive en la miseria vergonzante, la más dolorosa de las miserias". Y ese dinero se repartió así, pero sin que el nombre del maestro figurase para nada. Trabaja constantemente en su obra magna, La Atlántida, que será cantada en catalán... Obra de coros... Falla es un santo... Lo veremos en los altares (2006: 426).

En diciembre de 1935, durante su estancia en Montevideo, volvió a remarcar en una conversación con Alardo Parts la devoción que sentía por don Manuel. Al tiempo, explicó su forma y tempo de escribir:

Yo he aprendido del maestro Falla, que además de un gran artista es un santo, una ejemplar lección. En muchas ocasiones suele decir: "Los que tenemos este oficio de la música"... Hay artistas que creen que, por el hecho de serlo, necesitan medidas especiales para todas sus cosas... Yo estoy con Falla. La poesía es como un don. Yo hago mi oficio y cumplo con mis obligaciones, sin prisa, porque sobre todo cuando se va a terminar una obra, como si dijéramos cuando se va a poner el tejado, es un placer enorme trabajar poco a poco (García Lorca, 1977: 426).

Junto a Falla, uno de sus trabajos conjuntos fue la organización el famoso Concurso de Cante Jondo en Granada en 1922. Desarrollado en la Alhambra y organizado a la par por ambos, tuvo como consecuencia una elevación del status y consideración del flamenco 


\section{FEDERICO GARCÍA LORCA Y LA MÚSICA}

y dio como resultado, posteriormente, su famosísimo Poema del cante jondo. De esta forma, la finalidad del Concurso fue sacar a esta música del olvido a la vez que se le daba el puesto de gran creación musical que le pertenecía.

Ambos amigos contaron con el apoyo del Centro Artístico y Literario de Granada y de muy distintas personalidades del mundo de la música y del arte en general. Así, los organizadores enviaron una extensa carta al ayuntamiento de Granada el 31 de diciembre de 1921 firmada por nombres tan destacados de la música española del momento como Joaquín Turina, Tomás Borrás, Òscar Esplá, Adolfo Salazar, Bartolomé Pérez Casas o Enrique Fernández Arbós. En ella, ser recalcó la importancia del cante jondo y su influencia tanto en los cantos populares como en la música culta. Al tiempo, se denunció el desprecio que, desde ciertos ámbitos, se tenía sobre el flamenco en perjuicio de otros estilos con el peligro que ello conlleva, ya que es una labor muy compleja su trascripción en partitura.

La siguiente referencia que tenemos es de marzo de 1922 en una carta enviada al guitarrista Regino Sainz de la Maza. En ella, Lorca señalaba que el ayuntamiento granadino había decidido concederle el dinero necesario para organizar el festival. Además de comunicarle que ha mejorado bastante con la guitarra, se mostraban muy esperanzado de la organización del concurso: "vamos a hacer la fiesta más interesante que desde hace años se ha celebrado en Europa. ¡Todos estamos satisfechísimos!” (García Lorca, 2005: 100).

El 18 de junio de 1922, una vez finalizado el certamen, el propio Lorca escribió un artículo, Sobre el I Concurso de Cante Jondo, en el que ensalzaba los resultados obtenidos en un ciclo que se desarrolló con luna y lluvia, para el poeta el sol y sombra de los toros. En el escrito, subrayó la actuación de algunos intérpretes; también la falta de algunos artistas, en especial la de un cantaor, en presidio en esos momentos, y la de un guitarrista, que se había quedado manco poco tiempo atrás. Terminó el texto comentando: "ayer decía un hombre del pueblo: 'Ya se han acabao las fiestas', y tenía razón. Así además lo han comprendido las nubes" (García Lorca, 2006: 333).

\section{EL POETA Y LA INVESTIGACIÓN MUSICAL}

Otra de las vertientes más desconocidas para el público en general del granadino fue la de la investigación musical, ya que aprovechó los múltiples viajes que llevó a cabo por diferentes puntos de la geografía española en forma de giras con la compañía de teatro, visitas estudiantiles, a amigos o placer para realizar estudios y recopilar canciones y romances. En este sentido, cabe resaltar la definición que Lorca realizó del término canción: "las canciones son criaturas, delicadas criaturas, a las que hay que cuidar para que no se altere en nada su ritmo. Cada canción es una maravilla de equilibrio, que puede romperse con facilidad: es como una onza que se mantiene sobre la punta de la aguja" (García Lorca, 1977: 459). También es reseñable el término que Ramón J. Sénder otorgó a esta vertiente del poeta, 'folklorquismo'.

En definitiva, no pocos ensalzaron los grandes conocimientos y labor del granadino en este sentido. Jorge Guillén, en esta línea, apuntó que 


\section{MARCO ANTONIO DE LA OSSA MARTÍNEZ}

La memoria de Lorca es el más rico tesoro de la canción popular andaluza. Él ha recogido muchas, letra y canto, directamente. En esa dirección, su arte corre paralelo al de su gran amigo y maestro Falla. Por algo el sentido del ritmo de este poeta alcanza una variedad, una finura prodigiosa (1977: 55-56).

El gran repertorio que Lorca dominó se reflejó de forma nítida en su obra literaria. Incluso, en muchas de sus obras dio indicaciones acerca de las canciones que debían cantarse como parte integrante de su desarrollo. Ejemplos de ello son la 'Canción de las niñas' en Mariana Pineda y 'Canción de las Hilanderas', 'Coplas de la Criada', 'Copla del cortejo de bodas', 'Viejo romance infantil', 'Cantar de boda' y 'Canción de cuna' en Bodas de sangre, aunque solo incluyó los textos de las mismas.

Tal vez la consecuencia más subrayada de estos trabajos de campo se sitúa en el conjunto de discos que vino a denominarse como Canciones populares españolas, importantísimas por su repercusión en la vida musical de la España de la Segunda República y su llegada al cancionero republicano de la guerra civil española:

Junto con 'Granada', las Canciones Populares Españolas son los únicos testimonios en partitura y registrados en la Sociedad de Autores que Lorca legó. En el primer caso, se trata de una composición propia, mientras que en las grabaciones anteriores a cabo una armonización en la que colaboraron algunos amigos sobre las melodías que recopiló en trabajos de campo. Así, 'Zorongo gitano', 'Sevillanas del siglo XVIII', 'Los cuatro muleros', 'Nana de Sevilla', 'Romance Pascual de los Peregrinitos', 'En el Café de Chinitas', 'Las morillas de Jaén', 'Romance de los moros de Monleón', 'Las tres hojas', 'Sones de Asturias', 'Aires de Castilla' y 'Anda jaleo' compusieron una terna que, como apuntamos, fue muy difundida por diversos medios por toda España y Latinoamérica (Ossa, 2014: 111).

En estos cinco discos dobles de pizarra que editó el sello La Voz de su Amo en 1931, intervenía el propio Federico tocando el piano junto con la bailaora y cantante Encarnación López Júlvez, La Argentinita. Desde su puesta a la venta, tuvieron un gran éxito comercial y fueron muy difundidos en la radio, por lo que el dramaturgo también las incluyó a modo de fin de fiesta en algunas de sus representaciones teatrales. Así aparece relatado en el diario Crítica el 15 de diciembre de 1933, al hilo del estreno en Argentina de Mariana Pineda. Lorca planteó la interpretación y dramatización de las canciones como un entretenimiento final de notable interés artístico; también subrayó la importancia de lo que él denomina canción escenificada:

He querido hacer algo fino, digno, noble, con mucho sabor, pero con cierta estilización de arte. Durará alrededor de media hora, y se pasarán tres partes. La primera consistirá en la escenificación de "Los peregrinitos", así como suena, pues ésta es la 


\section{FEDERICO GARCÍA LORCA Y LA MÚSICA}

pronunciación popular y andaluza. Se trata de una de las canciones más difundidas del siglo XVIII español, un romance anónimo, que yo he arreglado para esta versión escénica. A continuación se pasará la conocida canción "Los cuatro muleros", y, finalmente, Lola Membrives interpretará un romance del siglo XVI, algo modernizado, que titularemos "Canción castellana". Yo considero que escenificar la canción, sobre todo estos romances, es una labor de más trascendencia que la que puede inferirse de su tono. La canción escenificada tiene sus personajes, que hablan con música, su coro, que juega el mismo papel que la tragedia griega. Por tanto, es dentro de un marco reducido, sobre todo tiempo, un espectáculo breve, pero completo, lleno de sugerencias y de bellezas (García Lorca, 2006: 455-456).

Para ello, se respetaba completamente el texto recopilado, aunque se repartía entre diferentes personajes. Además, en su puesta en escena se cuidaban los detalles en gran medida. Como consecuencia, el decorado, el vestuario y el valor que le otorgaba al cuerpo humano fueron premisas básicas en las representaciones de las canciones dramatizadas, como también las llamó:

Manuel Fontanals ha preparado unas decoraciones estupendas para las canciones y unos trajes que son deliciosos. Ya verán ustedes todo el espectáculo. En él se revaloriza el cuerpo humano, tan olvidado en el teatro. Hay que presentar la fiesta del cuerpo desde la punta de los pies, en danza, hasta la punta de los cabellos, todo presidido por la mirada, intérprete de lo que va por dentro (García Lorca, 2006: 461).

Lo mismo afirmó en una nueva entrevista al hilo de la representación de La zapatera prodigiosa en noviembre de 1933. En este caso también incluyó diferentes canciones en el desarrollo de la obra de teatro, por lo que no sólo aparecieron como fin de fiesta, sino que algunos ejemplos formaron parte integrante de sus dramas. Por su parte, La Argentinita, tras formar su propia compañía en 1932, realizó diferentes producciones con las Canciones populares españolas como base de propuestas coreográficas tanto en España como en el extranjero. En ellas incluía las 'Sevillanas del siglo XVIII' y 'El café de Chinitas', entre otras canciones. También realizó una versión coreográfica de El amor brijo, de Falla.

\section{LAS CONFERENCIAS SOBRE MÚSICA}

La actividad de Federico García Lorca en el ámbito de las conferencias y la relación que éstas tuvieron con la música es otro de los ámbitos de su carrera tal vez poco estudiados. No solo dictó en España un ingente número de comunicaciones en público sino que también las llevó a cabo en su estancia en Estados Unidos y en diferentes países de Latinoamérica y el Caribe, como Argentina, Cuba o Uruguay. Parece que, en las ocasiones en las que las dictó en público, Federico también tocaba el piano e, incluso, cantaba, ya que en esos momentos él era el único que podría ilustrar los comentarios que hacía. 


\section{MARCo ANTONIO DE LA OSSA MARTÍNEZ}

Quizá por su relevancia debemos subrayar El cante jondo, el texto que dedicó al que él mismo denominó como primitivo cante andaluz. En primer lugar, prestó un gran espacio en el mismo a tratar de eliminar tópicos y referencias vagas e imprecisas que se habían asociado a esta música, sobre todo por los no iniciados, un hecho a evitar en todo momento:

... son estos cantos, señores, los que desde el último tercio del siglo pasado y lo que llevamos de éste se ha pretendido encerrar en las tabernas mal olientes, o en las mancebías. La época incrédula y terrible de la zarzuela española, la época de Grilo y los cuadros de historia, ha tenido la culpa... en España país casi único de tradiciones y bellezas populares, era cosa ya de baja estofa la guitarra y el cante jondo (García Lorca, 1977: 1009).

Como se ha mencionado con anterioridad, Lorca fue un aficionado al flamenco. Antes del Concurso de Cante Jondo de Granada, acudió a numerosos tablaos y conoció no pocos cantaores. Si atendemos a la gran cantidad de discos que se conservan en la Fundación Federico García Lorca en la actualidad, podemos apuntar, incluso, que en su hogar familiar se escuchó flamenco de manera frecuente. De esta forma, en una carta que envió a Adolfo Salazar en agosto de 1921, él mismo comentó que estaba aprendiendo a tocar la guitarra con dos gitanos. Al tiempo, señaló la importancia que siempre le otorgó y el interés que siempre tuvo hacia esta música:

Además, (¿no sabes?), estoy aprendiendo a tocar la guitarra; me parece que lo flamenco es una de las creaciones más gigantescas del pueblo español. Acompaño ya fandangos, peteneras y er cante de los gitanos, tarantas, bulerías y ramonas. Todas las tardes vienen a enseñarme El Lombardo (un gitano maravilloso) y Frasuito er de la Fuente (otro gitano espléndido). Ambos tocan y cantan de una manera genial, llegando hasta lo más hondo del sentimiento popular. Y ves si estoy divertido (García Lorca, 1977: 83).

Quizá sea interesante reseñar una anécdota que aconteció en un recital protagonizado por la Niña de los Peines en la plaza de toros de Granada (con esta cantaora, además de mutua admiración, mantenía cierta amistad). Lorca siempre destacó, como se puede comprobar en la gran cantidad de testimonios que subrayan este cariz, por una personalidad afable, amable y comunicativa. En esta ocasión, mostró cierto carácter: "cuando la Niña de los Peines empezó a cantar, el público no guardaba silencio, la gente seguía hablando y riendo. Entonces García Lorca se levantó furioso mandando callar y le obedecieron" (Osorio, 2001: 179).

Retornando a su conferencia y siguiendo con claridad la estela y el juicio de Falla, el granadino diferenció entre cante jondo y flamenco tras atender, según su teoría, a su procedencia, forma y características (no hay que olvidar que el texto está escrito en el primer cuarto del siglo XX). Así, el primero provendría de los sistemas más antiguos, que a su vez derivan de diferentes naturalezas, ya que se centra en escalas no temperadas. 


\section{FEDERICO GARCÍA LORCA Y LA MÚSICA}

Mientras, el segundo se habría conformado en el siglo XVIII y tendría mayor presencia de sistemas temperados. Por tanto, el cante jondo, para Lorca, estaría formado por

...un grupo de canciones andaluzas cuyo tipo genuino y perfecto es la siguiriya gitana, de las que derivan otras canciones aún conservadas por el pueblo como los polos, martinetes, carceleras y soleares. Las coplas llamadas malagueñas, granadinas, rondeñas, peteneras, etc., no pueden considerarse más que como consecuencia de las antes citadas, y tanto por su arquitectura como por su ritmo difieren de las otras. Estas son las llamadas flamencas (García Lorca, 1977: 1004).

En la segunda parte de El cante jondo, subrayó una teoría de don Manuel en la que el gaditano señaló tres momentos básicos en el desarrollo y crecimiento de esta música en Andalucía y en España: la adopción del canto gregoriano por parte de la iglesia, la invasión árabe y, por último, la llegada de un grupo numeroso de gitanos que habrían huido de La India a partir del año 1400 tras sufrir persecución en su país de origen. De esta forma, arribarían a la península junto a árabes que viajaban desde diferentes puntos del norte de África.

Siguiendo su idea, solo en España se pudo desarrollar el cante jondo, ya que en otras zonas, como la de los Balcanes, no se encuentra una tradición musical similar. Por todo ello, el origen del canto se halla sin lugar a dudas en Andalucía. No serían las únicas influencias y músicas que se combinaron en el cante jondo. Una de ellas es la de cantos procedentes de la civilización bizantina, presente en el llamado rito hispánico en la iglesia católica.

Otra de sus conferencias fue Juego y teoría del duende. De ella conversó en una entrevista publicada en el diario La Nación en noviembre de 1933. Para Lorca, el duende es, en arte, el sabor que se introduce en el público. En el escrito, abogó por el empleo de un término que asocia a toda España y no va únicamente emparentado a la buena voz o al conocimiento de los estilos, sino a la llegada, al magnetismo y a la profundidad que despliega un músico o una composición. Además, el duende no sería solo característico del flamenco, sino que se puede atribuir a todas las músicas.

La siguiente, Arquitectura del cante jondo, está muy relacionada con la ponencia anterior. En esta ocasión, se centró en una buena parte del texto en la importancia de la guitarra en el desarrollo y devenir de la canción popular andaluza que, según el granadino, se ciñó en parte a la constitución tonal del instrumento. Por el contrario, en estilos como los martinetes y las jelianas, que se interpretan sin sonanta, la melodía y la forma cambian completamente. En lo referente al cante jondo, asocia un sentido de subordinación de la guitarra con respecto al cantaor. Pero las seis cuerdas deben tener su espacio en la falseta, ya que la guitarra debe acompañar, pero también crear. Como consecuencia, su aportación, recogida por la tradición, sería una especie de comentario que enriquece al cante. 


\section{MARCO ANTONIO DE LA OSSA MARTÍNEZ}

En estos escritos, los objetivos principales que Lorca se marcó a la hora de abordarlos eran mostrar su interés y amor por el flamenco y tratar de ascender su condición y consideración. Lógicamente, la gran calidad de su estilo literario queda patente en ellos. Por supuesto, debemos tener en cuenta la época en la que fueron redactadas y la mínima presencia de otros textos científicos relativos a esta música en su entorno. Setenta años después, Félix Grande señaló algunos errores, omisiones o descuidos supuestamente cometidos por Lorca en estos textos; eso sí, antes, señaló que fue el poeta que más profundamente ha sabido captar el mundo y el espíritu del flamenco.

En otro orden, las nanas también despertaron el interés de Lorca en el plano de las conferencias y las investigaciones. De esta forma, aprovechando los múltiples viajes que realizó por diferentes puntos de la geografía española trató de encontrar los elementos vivos, que para él eran dos, fundamentalmente: las canciones y los dulces. En ambos, según sus palabras, se refugia la emoción de la historia: "el amor y la brisa de nuestro país vienen en las tonadas o en la rica pasta del turrón, trayendo vida viva de las épocas muertas, al contrario de las piedras, las campanas, las gentes con carácter y aun el lenguaje" (García Lorca, 1977: 1074).

En esta conferencia señaló la recogida que protagonió de diferentes canciones de cuna de toda España. Su objetivo era conocer de primera mano las diferentes formas en que las mujeres españolas, madres, criadas, hermanas o abuelas, dormían a sus hijos, familiares o a los de sus jefes. En cuanto al origen de las nanas, su génesis se halla en el amor y la reciprocidad entre ambos, aunque también en algunos instantes de carga y desgana por parte de la madre o cuidadora.

Para el dramaturgo, en ellas son necesarios dos ritmos: el de la cuna o silla en la que se sitúa al niño y el que conforma la melodía, que se edifica sobre ambos para tratar de llegar al bebé y conseguir que duerma y/o repose. Por tanto, para Federico la letra en las canciones de cuna sería accesoria, en un primer momento: "no hacía falta ninguna que la canción tuviese texto. El sueño acude con el ritmo solo y la vibración de la voz sobre ese ritmo. La canción de cuna perfecta sería la repetición de dos notas entre sí, alargando su duración y efecto" (García Lorca, 1977: 1074).

La letra sirve para que el niño atienda a los labios de la cantante que, además le trasmite un sentido sobre el mundo, su cultura y un conjunto de emociones, dudas y miedos. Después, el poeta realizó una diferenciación entre las nanas españolas y otras de diferentes países que, aunque puedan aparecer como melancólicas en algunos instantes, para él lo son solo "accidentalmente, como un chorro de agua o el temblor de unas hojas en determinado momento. No podemos confundir monotonía con melancolía" (García Lorca, 1977: 1074). En definitiva, las nanas españolas poseerían en general un carácter de profunda nostalgia.

También consideró que la trascripción de melodías tradicionales que se había llevado hasta el momento en España no había sido del todo adecuada. Incluso, muchas de las pasadas a pentragrama se podrían considerar como no transcritas. Por tanto, se debían grabar en disco para poder conservar toda su riqueza y que se transmitieran y llegaran con 


\section{FEDERICO GARCÍA LORCA Y LA MÚSICA}

toda su frescura y realidad a la posterioridad. Tal vez por ello, no escribió en papel pautado más que un puñado de canciones:

No hay nada más delicado que un ritmo, base de toda melodía, ni nada más difícil que una voz del pueblo que da en estas melodías tercios de tono y aun cuartos de tono, que no tienen signos en el pentagrama de la música construida. Ya ha llegado la hora de sustituir los imperfectos cancioneros actuales con colecciones de discos de gramófono, de utilidad suma para el erudito y para el músico (García Lorca, 1977: 1087).

\section{CONCLUSIONES}

Sin duda, la relación de Lorca con la música es muy estrecha; también magnética para cualquier investigador e interesado. Así, hemos tratado de dibujar unos breves trazos acerca de su gran relación con el acervo popular y tradicional y con el flamenco. Es un campo muy amplio en el que, única y humildemente, hemos pretendido acercarnos con interés y devoción. Lo cierto es que, en su vida, el arte de Orfeo ocupó un lugar de privilegio ya desde sus primeros años de estudiante, en los que era considerado como músico y su vocación caminaba más cercana al piano que a la pluma y al papel.

Pero, incluso cuando se decantó en mayor medida por la literatura, la música ocupó un espacio muy relevante en su obra y en su devenir por el mundo. No solo se relacionó con grandes personalidades de la música de su momento, sino que fue muy frecuente verle cantar y tocar el piano. Aparte de las composiciones que esbozó, también se dedicó a la investigación, e incluyó en muchos de sus teatros un buen número de canciones. En este sentido, su trabajo en la compañía de teatro aficionado La Barraca fue muy subrayado, ya que la música poseyó una enorme importancia en sus montajes. Del mismo modo, la edición de las Canciones populares españolas en el sello La Voz de Su Amo junto a La Argentinita en 1931 supuso un nuevo punto de inflexión en su carrera musical: no solo fueron radiadas y escuchadas en numerosos puntos del globo, sino que también las tomó como punto de partida para llevar a cabo diferentes propuestas en sus representaciones teatrales a modo de fin de fiesta.

En cuanto al flamenco, desde su juventud se acercó con interés a esta música. Así, colaboró abiertamente en el I Concurso de Cante Jondo que, si bien fue criticado por algunos sectores, logró muchos de los objetivos que se marcaron antes de su organización. También tuvieron una gran importancia las conferencias que dedicó al cante jondo y al duende. Quizá las realizó partiendo de su intuición y sensibilidad, y de las muchas conversaciones que mantuvo con Manuel de Falla y diferentes músicos de distintas órbitas sobre el flamenco. Lo cierto es que su nivel literario destaca por sí solo, aunque no hay que olvidar su gran temperamento musical. Tal vez se deba, como apuntó Elena Torres, a que “en Federico García Lorca, música y poesía son, aún más si cabe, indisociables (2010: 72). 


\section{MARCO ANTONIO DE LA OSSA MARTÍNEZ}

\section{BIBLIOGRAFÍA Y REFERENCIAS DISCOGRÁFICAS}

García Lorca, F.; La Argentinita (1994). Colección de Canciones Populares Españolas. \{Grabación sonora\}. Madrid: Sonifolk.

García Lorca, F. (1977). Obras completas. Bilbao: Aguilar.

García Lorca, F. (2005). Obras completas. IV. Barcelona: RBA.

García Lorca, F. (2006). Obras completas. III. Barcelona: RBA.

García Lorca, F. (2007). Obras completas. VI. Barcelona: RBA.

García Lorca, F. (1999). Federico y su mundo. Barcelona: RBA:

Gibson, I. (1987). "Lorca y la música. La música en la generación del 27”. En Homenaje a Lorca, pp. 81-83. Madrid: Ministerio de Cultura.

Gibson, I. (2003). Vida, pasión y muerte de Federico García Lorca. Barcelona: Ediciones Folio.

Guillén, J. (1977). Prólogo. En F. García Lorca, Obras completas. Bilbao: Aguilar.

I Concurso de Cante Jondo. Grabaciones originales. Colección Manuel de Falla. Granada, Corpus de 1922. Colección Federico García Lorca. Discografía flamenca utilizada por el poeta. \{Grabación sonora\} (1997). Madrid: Sonifolk.

Martín, A. (2010). "La generación literaria del 27 y la música: Jorge Guillén y Federico García Lorca”. En C. L. García, F. Martínez y M. Hilillo, (coord.), Los músicos del 27, pp. 53-69. Granada: Universidad de Granada.

Osorio, M. (ed.) (2009) Miedo, olvido y fantasía. Granada: Comares.

Ossa, M. A. de la (2014). Ángel, musa y duende: Federico García Lorca y la música. Madrid/Cuenca: Editorial Alpuerto/Servicio de Publicaciones de la UCLM.

Persia, J. de (1992). I Concurso de Cante Jondo, 1922-1992. Edición conmemorativa. 1922-1992: una reflexión crítica. Granada: Archivo Manuel de Falla.

Persia, J. de (1999). “Lorca, Falla y la Música. Una coincidencia intergeneracional”. En S. Zapke (ed.), Falla y Lorca. Entre la tradición y la vanguardia, pp. 67-89. Kassel: Edition Reichenberge" 


\section{FEDERICO GARCÍA LORCA Y LA MÚSICA}

Tinell, Roger D. (1993). Federico García Lorca y la música. Madrid: Fundación Juan March.

Torres Clemente, E. (2010). Vocaciones cruzadas: músicos y poetas de la Generación del 27’., en C. L. García Gallardo, F. Martínez González y M. Ruiz Hilillo, (coords.), Los músicos del 27, pp. 70-92 Granada: Universidad de Granada.

Valls Gorina, M. (1962). La música española después de Manuel de Falla. Madrid: Revista de Occidente.

Fecha de recepción: 09/03/2018

Fecha de aceptación: 26/06/2018 